\title{
Competitiveness of healthcare institutions of regional clusters in the global crises era of COVID-19
}

\author{
Natalia Pashkus ${ }^{1, *}$, Nadegzda Starobinskaya ${ }^{1}$, and Petr Shvetc ${ }^{2}$ \\ ${ }^{1}$ Herzen State Pedagogical University, Institute of Economics and Management, Department of \\ Industrial Economics and Finance, the Moika river emb., 48.St. Petersburg, Russia \\ 2 Saint Petersburg State University, Faculty of Economics, Department of Economics \& Economic \\ Policy, University embankment 7-9, 199034, St Petersburg, Russia
}

\begin{abstract}
Background of the study: In the current situation of the global COVID-19 pandemic the role of a strong medical cluster operating in a specific territory in a specific region or even in a country is incredibly increasing. A strong regional medical cluster in these conditions determines the level of health of the population, the ability to cope with the serious challenges of the pandemic and minimize its negative consequences, both the health of citizens and the economy of the region.

Purpose of the article: The purpose of this paper is to determine the factors that have the strongest impact on the competitiveness of medical organizations in the region in the new conditions of a pandemic and its consequences, as well as to identify promising mechanisms for its assessment and ranking.

Methods: In this work, methods of statistical, strategic and matrix analysis are used, on the basis of which the factors of competitiveness of healthcare organizations in the region can be determined and ranked, which makes it possible, by ranking, to identify the most significant of them during the COVID-19 pandemic and its consequences.

Findings \& Value added: The results of this study made it possible to test new mechanisms for assessing the competitiveness of healthcare institutions in the new conditions of a pandemic and to study the influence of the most significant factors of competitiveness on the regional and global competitiveness of the region in the conditions of COVID-19.
\end{abstract}

Keywords: medical organization, competitiveness of institutions, pandemic, medical services, regional health system.

JEL Classification: $I 11, H 51, I 18$

\footnotetext{
*Corresponding author: nat_pashkus@mail.ru
} 


\section{Introduction}

In the context of the COVID-19 pandemic, countries are becoming increasingly dependent on the efficiency of their health systems. Consequently, the problem of ensuring the high competitiveness of medical organizations of various types and the high quality of their services is moving from the sphere of sectoral interests to the sphere of interests of the national economy and the country's security in the global economy. The quality of the country's health care systems determines the work opportunities of all other sectors of the economy, the mode of operation, the level of staffing, the conditions of functioning, which depend on how each medical organization individually and the entire health care system as a whole fulfill their purpose and maintain the health of citizens.

The experience of the pandemic has shown that the level of financial support of healthcare in a country does not always determine the quality of the country's medical system. Economically strong countries that make significant contributions to the operation of their health care system, in some cases, at a certain stage of the pandemic, completely failed to cope with its course or experienced many successive crises and even collapses. (Asadulaev, 2021) A number of European countries, and countries whose health care system was considered before the pandemic, if not the best, then an example to follow, for example, Italy, Switzerland, Great Britain, Sweden, Germany, were forced to revise both the structure of medical services and the adopted regulations, and to change the system of state support for medical organizations that existed before the pandemic. A similar situation occurred in the United States, where catastrophically high rates of morbidity and mortality from COVID-19 were recorded for a long time. (Maani and Galea, 2020; Diez Roux, 2020) Moreover, when we talk about state support, we mean not only the financing of the work of medical and research organizations of a medical profile, but also the system of state regulation and state participation in the work of the system.

Thus, the financing of the healthcare system and specific medical organizations is an important condition for their normal functioning, but not the only factor contributing to their effective work. Moreover, there are examples of organizations that, despite the huge financial resources, have not been able to achieve their goals or have achieved them to a large extent formally. Thus, the Anglo-Swedish pharmaceutical company AstraZeneca had significantly greater financial resources than all the combined resources of Russian research centers combined, and the company's research base was based on the structures of such strong research centers as Cambridge. However, the organization was too hasty to carry out the commercial promotion of the drug and did not carry out the necessary tests for the possibility of side effects. And even for a long time she kept silent about the level of insecurity, in terms of the occurrence of undesirable side effects from vaccination with her drug.

Many countries are quite aggressively promoting their vaccines on the global market, and some even actively use black PR to create a misconception about the effectiveness and side effects of competing vaccines. All this contributes to whipping up fears among the population of different countries and stimulates the movement of" anti-vaccinators " all over the world. Such sentiments lead to an artificial slowdown in the pace of vaccination in the world, even in those countries that themselves have vaccines and have a sufficient base to produce the necessary volumes of drugs for free vaccination of their own population, and possibly have the opportunity to carry out commercial supplies of vaccines abroad. Thus, the competitive struggle of countries and their pharmaceutical companies that have their own COVID-19 vaccines actually prevents an effective way out of the global pandemic crisis. These competitive wars also hinder the normal relationship between countries, since the mutual opening of borders is hindered by political games and formally rests on the mutual recognition of drugs used in different countries for vaccinating the population. Consequently, the restriction of population movements between countries is increasingly associated with 
political reasons, rather than the requirements of a pandemic, but is formally explained precisely by the epidemiological situation and mutual distrust of the quality and effectiveness of vaccines.

And yet, despite all the problematic situations and incorrect behavior of the participants, those medical or pharmaceutical organizations that realized their innovative potential were able to provide a significantly higher level of competitiveness and ensure high quality of medical services. It should be noted that in the context of a pandemic, medical and pharmaceutical companies should be considered in cooperation. Usually, the pharmaceutical market was considered independently. The pharmaceutical sector of the economy was completely commercial, although it was regulated by the state. At the same time, medical institutions could be both budgetary and private, while referring to the public sector of the economy. Now it is necessary to recognize that all these organizations are interdependent participants in the health care system, since without timely supply of drugs, development and release of vaccines, full-fledged supply of medical institutions with everything necessary for work, the latter will not be able to provide their services at the proper level of quality. Without support from pharmaceutical companies, medical institutions will not be able to maintain uninterrupted operation, maintain a medical base and organize timely visits to patients. Moreover, research organizations of medical or pharmaceutical profile also become natural market participants, since they are the ones who identify new methods of treatment, develop drugs and medical devices, conduct research in the field of the course of diseases and their mutations. Consequently, without strong research centers, modern medicine will not be able to function, or it will be dependent on the results of the activities of foreign research organizations, as well as political processes taking place between countries. A number of countries with a seemingly strong health care system have become hostage to political processes, when they are not free to choose vaccination drugs according to their objective effectiveness, and the purchase of necessary pharmaceutical drugs occurs with significant delays and not always at reasonable prices. This situation contributes both to a decrease in the efficiency of the world's medical systems, and provokes waves of mutual claims and dissatisfaction between countries with each other. It should be noted that one of the most important reasons for the current state of affairs is connected with the distrust of countries to each other, as well as the distrust of their populations to medical workers, organizations that they represent, as well as health systems in general, and even more so, the health systems of other countries.

The trust factor becomes a key motivating element in ensuring the effectiveness of providing medical care to the population and the implementation of medical services by specific healthcare organizations. In modern conditions of a pandemic, an interesting phenomenon can be observed at the level of a single country. The growth of public confidence in medical professionals, the growth of the prestige of the medical profession in society, the increase in confidence in the activities of specific medical, pharmaceutical or research organizations, leads to an increase in the perceived quality of their services, and, as a result, an increase in the actual quality and competitiveness of organizations. It should be noted that a similar phenomenon that occurs during a pandemic has already been noted by some authors. For example, a team of authors (Darin Christensen, Eidrila Dube, Johannes Haushofer, Bilal Siddiqui and Martin Voors) conducted a study of the quality of health systems during the pandemic (Christensen et al., 2021). As an experimental base, the authors used data from Sierra Leone, where an outbreak of the Ebola virus occurred in 2014. The authors argue that the existing skepticism about the quality of health systems and, as a result, insufficient access to them, contribute to high mortality rates in developing countries. Indeed, the perceived quality of medical services begins to play a key role during epidemics, because people choose according to it whether to cooperate with medical professionals and, especially, advanced specialists and leading medical organizations. The authors conducted a 
study of the dependence of improving the perceived quality of medical care and the ability of the healthcare system to strengthen the health of the population and effectively combat the course of the epidemic. As a result of the conducted research, it was found out that ensuring high public confidence in medical workers and specific medical organizations contributes to an increase in the number of appeals at the initial stage of the onset of symptoms of the disease, timely provision of medical care, and, therefore, a decrease in mortality and an increase in the actual quality of medical services. Similar conclusions were obtained in the article (Miller et al., 2021). This article is devoted to the analysis of the results of a largescale US federal survey related to the identification of the relationship between the state's entry into the Medicaid program and mortality in this state after joining the program. The conclusions presented in the article also demonstrate the role of the trust factor in ensuring the effectiveness of the regional health system.

The Russian experience of the pandemic shows that the increase in the indicator of confidence in the activities of doctors and the work of research, pharmaceutical and medical organizations led to a spontaneous jump in innovative activity in this area. Medical and pharmaceutical research in Russia as a whole and in the North-Western region was considered a priority even before the pandemic. Consequently, even before the pandemic, these studies received priority funding. However, during the pandemic, when the work of doctors became critically important, and the daily feat of doctors saved many lives, there was a qualitative leap of confidence, both for patients of medical institutions and their relatives, and for the population as a whole. Under these conditions, those medical institutions that had a developed innovative potential and demonstrated a high level of dedication of staff at all levels and high quality of medical activity, and its effectiveness in the recovery of patients, stood out vividly. Similarly, in the research sector, there are organizations that are able to carry out a comprehensive study and development of a drug, medical device or treatment mechanism that demonstrates high efficiency in combating the severe course and negative consequences of the disease. If there is a proper level of funding that guarantees the achievement of the desired results, a high level of confidence in the activities of specific organizations was a motivating factor that spurred the transition to a higher level of competitiveness of the organization.

\section{Methodology}

Consider the change in the system of indicators of the competitiveness of medical institutions in the context of the global crisis caused by the COVID-19 pandemic, and demonstrate their application by the example of assessing the competitiveness of a number of leading medical institutions in St. Petersburg and the Leningrad region. The region has historically been characterized by a high level of development of the medical and pharmaceutical cluster. Many medical institutions in the region were not only medical, but also innovative research organizations. The increase in the level of trust in the organization contributed to the growth of motivation for the work of medical workers and provided an impetus for the activation of their innovative activity. However, those organizations that were not characterized by a tendency to innovate, in the conditions of the pandemic, showed an increase in serious work violations, an increase in the number of medical errors and negligent attitude to patients. It should be noted that the financing conditions for all medical institutions in the region improved significantly during the pandemic, which concerned both financing the renovation of the material and technical base and paying for the work of medical personnel, especially those working in the "red" zone with COVID-19 patients. Consequently, all medical organizations in the region had opportunities for increasing competitiveness in response to the increase in funding. 
As noted above, the system for assessing the competitiveness of healthcare organizations in the context of a global pandemic should undergo certain changes. The assessment should take into account two types of parameters: an assessment of the competitive status of organizations and the attractiveness of the segment of the medical market in the region where this organization operates. The first group of indicators characterizes the internal dependent characteristics of the organization's activities and evaluates the indicator of the horizontal coordinate axis of changes in competitiveness. The second group characterizes the state of the market segment and takes into account external factors that are independent of the medical organization, which it is forced to take into account in its work. This group of parameters determines the position of the organization along the vertical coordinate axis. The mutual location of the competitive positions of medical organizations and their compliance with the areas of the competitiveness matrix determines the status of the organization and the recommended strategies for its development.

So, the first group of evaluation indicators included in the analysis of the competitive status of a medical organization should include the following characteristics:

1. The relative market share and the degree of dispersion of income from nonbudgetary activities (paid medical services, grant activities, other forms of entrepreneurial activity of medical institutions) relative to the main competitors

2. The ability to carry out innovative activities and to obtain and use their results in the main activity of a medical organization;

3. The ability to provide medical and accompanying services of high perceived and actual quality and the level of accessibility of medical services for all categories of patients in need;

4. Technological, logistical and personnel advantages;

5. Marketing advantages, the image of the institution, including innovative, as well as the level of loyalty of the organization and its medical staff to patients, stakeholders and the state;

6. The level of management and the ability to purposefully activate innovative activities in the organization at all levels;

7. Knowledge of the consumer of the health system services and the market of medical services in the region;

8. Flexibility in the provision of medical services, implementation of innovative and other types of activities.

The second group of indicators of the activity of a medical organization, which characterizes its market parameters, includes the following factors:

1. The size of the medical market in the region and the growth rate;

2. Features of competition in the medical market sector of the region;

3. Opportunities and conditions for attracting additional funding by healthcare institutions in the region, including from innovative activities;

4. Long-term and peak (caused by crises and epidemics) requirements for technologies, investments and innovative activity of medical organizations in the region;

5. Barriers to entry and exit to a specific market position, including in the field of innovative medical developments;

6. Seasonality and cyclicity of the processes of providing medical services and conducting additional activities of medical institutions, including innovative ones;

7. Requirements for the work of medical organizations and the results of their activities, in particular, the level of control in the healthcare system of the region;

8. Interaction of the external environment in the health system of the region, including those caused by global crises and pandemics. 


\section{Results}

The proposed system of indicators was used in the authors ' study of the competitiveness of a number of healthcare institutions in St. Petersburg and the Leningrad region. The choice of healthcare organizations was carried out in accordance with the priorities of consumers and the image of the organization, from the point of view of all its consumers and stakeholders, as well as previously recorded high competitive positions. The results of the study are presented in Figure 1.

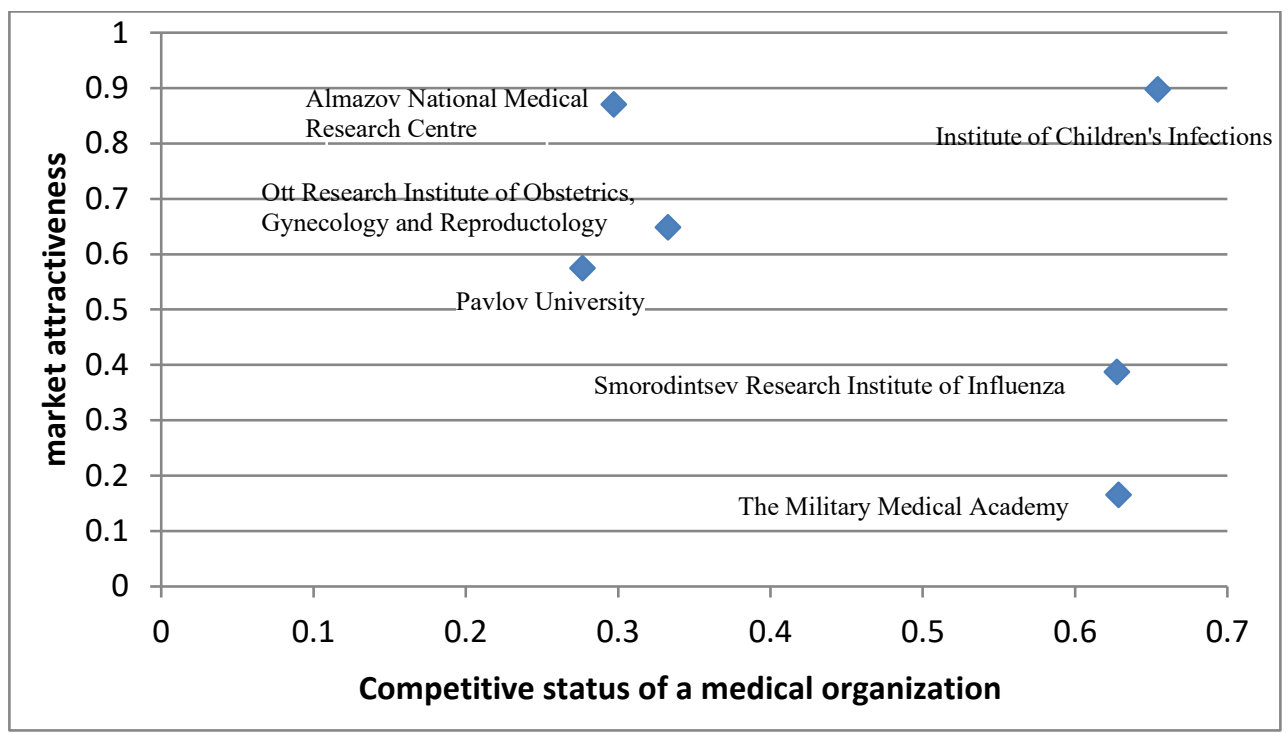

Figure 1. The matrix of competitiveness of medical organizations in St. Petersburg

The analysis showed that the leading position is occupied by the Institute of Children's Infections, which fell into the field of Winner No. 1, corresponding to an effective strategy for ensuring competitiveness. The achievement of this position by the organization is associated with a strong innovative potential and the ability to implement the results of innovative activities in all processes of the organization. Almazov National Medical Research Center, which also specializes in innovative activities, but is inferior to the Children's Scientific and Clinical Center for Infectious Diseases of the Federal Medical and Biological Agency (Institute of Children's Infections) in terms of loyalty and availability of medical services for all categories of the population, took the second place in terms of competitiveness in the category of Winner No. 2. Smorodintsev Research Institute of Influenza and The Military Medical Academy, which is significantly lower, fall into the category of Winner No. 3. This category of medical organizations may lose their competitiveness potential due to a partial loss of innovative activity or a significant expansion of the range of their commercial activities with a departure from their main socially significant function. Ott Research Institute of Obstetrics, Gynecology and Reproductology and Pavlov First Saint Petersburg State Medical University (Pavlov University) were in the Intermediate category No. 2, that is, the most average position in terms of competitiveness. The strategic position of these medical institutions is currently very unstable, which only intensified during the COVID-19 pandemic and may contribute to the further loss of competitive positions. This situation of medical institutions is associated with their constantly slowing down level of innovation activity, an increase in the number of problematic situations that cause a decrease in the level of consumer confidence and a decrease in the image of innovative medical organizations. 


\section{Discussion}

The system of assessing the competitiveness of healthcare organizations can be applied to the analysis of the competitive positions of healthcare institutions within the framework of regional healthcare systems in Russia. In principle, it can also be used for a comparative analysis of medical institutions. At the same time, there are certain restrictions related to national legislation, regional regulations and the level of state regulation of the healthcare system, which limits certain opportunities for the development of medical organizations.

The above model takes into account some characteristics of the state economic policy. At the same time, the active use of protectionist measures and import substitution policies (Fajgelbaum et al., 2020; Aliaskarova et al., 2020) leads to a certain distortion of the significance of the criteria, which requires constant revision of the results and complicates their comparability. The problem is also aggravated by the costs of monopolization as the reverse side of narrow specialization. (Kotcofana et al., 2020)

One of the problems of the wide application of this methodology may be a low level of information openness (including due to the Law on the Protection of Personal Data) and not complete comparability of information. Under these conditions, the study of advanced medical organizations of the regional health system may fall into the "learning traps" described by Annie Liang and Xiaosheng $\mathrm{Mu}$, when researchers "get stuck observing suboptimal sources and information aggregation is ineffective" (Liang and Mu, 2020). All this, in turn, leads to numerous distortions in the ratings (when biased estimates are taken or ratings reflecting "imaginary reality" (Klapkiv et al., 2020; Kislitsyna et al., 2020). It can be noted that numerous studies of the information economy predict such distortions (Kamenica, 2017; Balandina et al., 2020).

The impact of such traps in the information society is exacerbated by fake information (Massey et al., 2018) and unclear performance criteria (Pashkus et al., 2017a), which leads to an insufficient level of investment in the system (Maani and Galea, 2020). Often in such countries, the basic principles are formed under the influence of populist trends in politics, and the necessary research is frankly late. (Rodrik, 2018, Harstad, 2020) As a result, the wrong priorities form the basis for the development of healthcare (Cooper et al., 2019; Harris, 2018; Pashkus et al., 2017b), which leads to absurd results, for example, that it is better to treat healthy people than sick people (Kitagawa and Tetenov, 2018). These factors led to the actual collapse of the health systems of a number of countries during the pandemic (Diez Roux, 2020; Asadulaev, 2021).

All this requires further research of the above methodology and analysis of its application for different regions and countries.

\section{Conclusion}

In general, the analysis showed that during the global crises caused by the COVID-19 pandemic, the structure and composition of parameters that have a strong impact on the competitiveness of medical organizations are changing. The most significant factors in these conditions are not the level of financing, which is of a secondary nature, although it is necessary, but the level of trust on the part of all stakeholders and consumers, as well as the ability to implement and implement the results of innovative activity in all processes. Therefore, in order to overcome potential crisis phenomena in the healthcare system in a timely manner and prevent a drop in the level of competitiveness of national healthcare systems in the context of a global pandemic, it is necessary to pay close attention to ensuring that leading healthcare institutions meet these two criteria and create conditions for their maintenance in the structure of competitiveness, as well as replicating the experience of ensuring the competitiveness of these medical organizations for the entire medical cluster. 


\section{Reference}

1. Aliaskarova, Z., Pashkus, V., \& Blagikh, I.A. (2020). Proactive Industrial Policy as the Main Strategy for Improving Russia's Competitiveness in the Context of Global Economic Processes. SHS Web of Conferences, 74, 06002.

2. Asadulaev A., Starobinskaya N., \& Shvetc P. (2021). Competitiveness of Regional Health Systems and Specific Medical Organizations in the Context of the Coronovirus Pandemic. SHS Web of Conferences, 92, 01041

3. Balandina, D.M., Aliaskarova, Z.A., \& Ignatova, A.M. (2020). Digital economy: developmental characteristics and consumer behavior. Izvestia of the International Academy of Agrarian Education, 52, 59-63.

4. Christensen, D., Dube, O., Haushofer, J., Siddiqi, B., \& Voors, M. (2021). Building Resilient Health Systems: Experimental Evidence from Sierra Leone and The 2014 Ebola Outbreak. The Quarterly Journal of Economics, 136(2), 1145-1198.

5. Cooper, Z., Craig, S. V., Gaynor, M., \& Van Reenen, J. (2019). The Price Ain't Right? Hospital Prices and Health Spending on the Privately Insured. The Quarterly Journal of Economics, 134(1), 51-107.

6. Roux D. A. V. (2020). Population Health in the Time of COVID-19: Confirmations and Revelations. The Milbank Quarterly, 98(3), 629-640.

7. Fajgelbaum, P.D, Goldberg, P., Kennedy, P.J., \& Khandelwal, A. (2020). The Return to Protectionism. The Quarterly Journal of Economics, 13(1), 1-55.

8. Harris, M.C., \& Kohn, J.L. (2018). Reference Health and the Demand for Medical Care. The Economic Journal, 12(615), 2812-2842.

9. Harstad, B. (2020) Technology and Time Inconsistency. Journal of Political Economy, 128(7), 2653-2689.

10. Kamenica, E. (2017). Information Economics. Journal of Political Economy, 125(6), 1885-1890.

11. Kislitsyna, O. A., \& Chubarova, T. V. (2020). The Use of Composite Indices to Measure the Activities of the Health Care System: The International Experience. Problems of modern economy, 2, 100-104.

12. Kitagawa, T., \& Tetenov, A. (2018). Who Should Be Treated? Empirical Welfare Maximization Methods for Treatment Choice. Econometrica, 86(2), 591-616.

13. Klapkiv, Y., Vovk, V., \& Klapkiv, L. (2020). Comparative Analysis of the Health Care Institutions' Competitiveness Level. Montenegrin Journal of Economics, 16(3), 69-82.

14. Kotcofana, T., Altunyan, A., \& Bazzhina, V. (2020). The impact of monopolism on the stability of economic development in the conditions of globalization. SHS Web of Conferences, 74, 06013.

15. Lian,g A., \& Xiaosheng, M. (2020). Complementary Information and Learning Traps. The Quarterly Journal of Economics, 135(1), 389-448.

16. Maani, N., \& Galea, S. (2020). COVID-19 and Underinvestment in the Health of the US Population. The Milbank Quarterly, 98(2), 239-249.

17. Massey, G., Kliestikova, J., Kovacova M., \& Dengov, V.V. (2018). The Perceived Accuracy of Fake News: Mechanisms Facilitating the Spread of Alternative Truths, the Crisis of Informational Objectivity, and the Decline of Trust in Journalistic Narratives. Geopolitics, History and International Relations, 10(2), 37-43. 
18. Miller, S., Johnson, N., \& Wherry, L.R. (2021). Medicaid and Mortality: New Evidence From Linked Survey and Administrative Data. The Quarterly Journal of Economics, 136(3), 1783-1829.

19. Pashkus, V., Pashkus, N., \& Chemlyakova, A. (2017a). The Problem of Quality Correlation and Efficiency of Medical Services as a Factor of Health Organizations Competitiveness. CBU International Conference Proceedings 2017. Prague, Czech Republic, 366-370.

20. Pashkus, V., Pashkus, N., \& Chemlyakova, A. (2017b). Model for Assessment of Healthcare Institutions' Competitiveness. CBU International Conference Proceedings 2017. Prague, Czech Republic, 361-365.

21. Rodrik, D. (2018). Populism and the economics of globalization. Journal of International Business Policy, 1, 12-33. 